\title{
Pathologic Response
}

National Cancer Institute

\section{Source}

National Cancer Institute. Pathologic Response. NCI Thesaurus. Code C123626.

An evaluation of the pathologic response of the disease to the therapy. 